\title{
Study on Model Construction of Gray Correlation Method Based on Probability Theory and Mathematical Statistics
}

\author{
Juan Deng \\ Tourism and Culture College, Chongqing Technology and Business Institute, Chongqing, China \\ d_eng_juan@126.com
}

Keywords: model construction; gray correlation analysis; optimization model; empirical research; ability promotion; influencing factor

\begin{abstract}
Active emotional education and the ability promotion of higher vocational English learning are closely related to the improvement and effectiveness of English education. In the face of the particularity of the higher vocational education. In accordance with his rich teaching experience over many years in the field of English education, research experience and practice survey, the author structured model based on emotional education in order to improve English learning ability in vocational colleges.In further, by using grey correlation analysis to optimize the subjective energy efficiency performance of the model, the author tried to improve English learners' learning ability and offer new learning concept for English learners, which provides the theory basis of research and explored path in this field for educational workers.
\end{abstract}

\section{Introduction}

Emotional education is main part of modern education, it means that pay attention to student's emotion change in the student education teaching, caring about that the education for students' selffulfillment maximization on the basis of keeping an eye on the student individuals and their all-round development [1]. But emotion in western culture is considered the typical dangerous things, was some dirt-cheap reasons and need to maintain a well-founded check. Nowadays, such as some moral and higher social behavior in emotions occupies a hallowed place in study (Hoffman, 2001). Its importance in the developing education also quickly got recognition (Toomey, 2005) [2]. This paper mainly researched it is the role that emotional education played in developing the higher vocational English learning capability education teaching practice. In the face of the particularity of the higher vocational education group, the importance of emotional education in the English education was especially outstanding, most higher vocational students' English strength were weak, in the English learning process was easy to appear the chronic disease such as depression, dislike English learning, then the emotional education in higher vocational English teaching would play a very good entrainment. In the teaching process to respect the students' self-esteem, pay attention to training students' emotional self-control ability, urging them to get a positive emotion influence on all things around them in life, when the emotional experience in joy, the learning process would be in a positive state[3]. At the same time it is not only the knowledge learning, but also students' perfect personality in train and the noble moral sentiment in the learning English knowledge, owned the health world outlook and outlook on life, became the genuine excellent professional students on virtue, wisdom, body, beauty and labor all-round development. In the actual learning process to make students serve as main role in the whole teaching process, tried to pay attention to students' emotional change, focused on the heuristic and openness of English teaching in the student active learning circumstance, paid attention to training higher vocational students' English learning subjective initiative and improve the students' English result. Constructing the developed higher vocational English learning capability model based on emotional education was that make students into full play in emotional initiative in higher vocational English teaching, made higher vocational students in English learning process didn't passive, accepted negatively outside to study the influence of emotion, but actively, applied their own rich feelings to accept English teachers' teaching and autonomous learning. 


\section{The cognitive research of emotional education for higher vocational students}

In order to better building emotional education and developing higher vocational English learning ability model, we have several questionnaire survey on vocational college students. Through the investigation mainly understand the students' cognitive situation to the emotional education, the instructors' applied actuality of emotional education in the process of teaching education[4]. The investigation of actual situation is in order to construct the model in improving higher vocational English learning capability based on emotional education, the thorough understand students' learning motivation fully, the present situation of English learning, we further to boost laying a solid foundation on model construction and the teaching methods reform,. After the completion of questionnaire survey, in order to make more scientific statistics, we took the random extraction methods, the issued 5000 questionnaires randomly selected 500 as sample, and statistics. The results showed that $89 \%$ students thought that higher vocational education need to emotional education, only a few students thought it doesn't matter, more than $78 \%$ students said emotional education needed to pay more attention in higher vocational education, and the specific results as below.

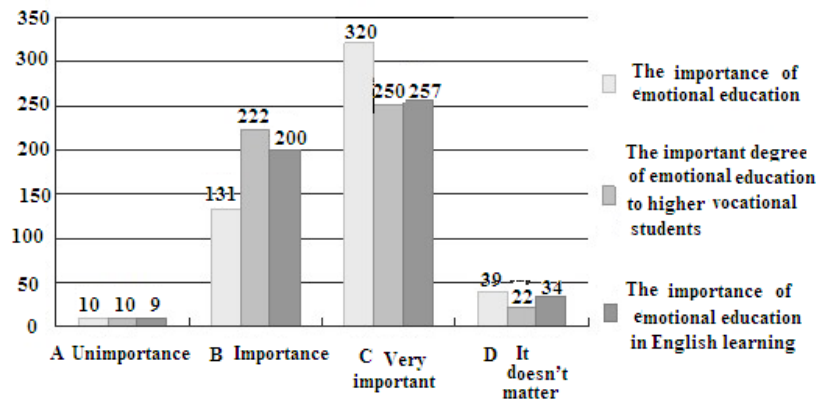

Figure 1. The cognitive research of emotional education on higher vocational students

From Figure 1, more than 400 students thought that emotional education was very important, there was only 10 students didn't feel important and 39 students didn't matter; The important degree of emotional education for higher vocational students was also very high, including 10 students feel emotional education for higher vocational students without necessary, but more than 450 students thought that emotional education for higher vocational students were important. Higher vocational students had rich high enthusiasm on emotional education; know that the positive role of emotional education in higher vocational learning, clear that the far-reaching significance in emotional education for particularity education on higher vocational education group, the vast majority of students support the emotional education to used in education teaching. In English teaching education survey on the application of emotional education, most of the students were support, the specific is as below.

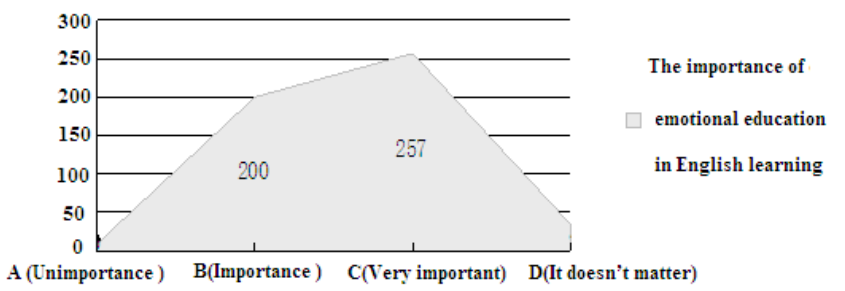

Figure 2. The higher vocational students' cognitive research in application of emotional education in English teaching

In English education teaching nine students didn't feel important in the application of emotional education, 200 students thought that emotional education in English learning was important, very important students accounted for 257, there were 34 students thought doesn't matter. In investigation can be found that $91.4 \%$ students thought that emotional education was recommendable in English study[5]. So emotional education in the application of improving higher vocational English capability is science, is accordance with higher vocational students' learning psychological anticipation.

\section{Construction on model of improving higher vocational English learning capability based on emotional education}

With the development of society and the progress of the times, educational workers should renew the education idea, theory with practice, pay attention to the practice of students characteristics 
targeted teaching in the current era, especially the current higher vocational English education, the object of higher vocational English education mostly was for students' weak English learning foundation in English education process, must establish the education thought take the student as the center, pay attention to emotional education[7].

Today's university students all have significant temperamental difference, personality is distinct, affect rich etc. At the same time higher vocational students have English skill weak, the word quantity is little, oral English is poor etc, in view of these characteristics, the teacher in the higher vocational English education teaching needs the students' perceptual cognition, based on the emotional education, carefully systematic observe the students' learning dynamic, with practice, analysis, induction, innovation and summary, to construct improving higher vocational English learning capability model based on emotional education ,which can be shown in Figure 3.

As shown in Figure 3, the improved higher vocational English learning capability model based on the emotional education constitute by cycle stage learning, including the definition of emotion education in application of English teaching, the application of different grade students' live investigation and analysis, comprehensive evaluation, model analysis and update building, circulation, etc[9]. Need to define the importance of emotional education in the higher vocational English education firstly in the practical teaching applying process, such as teaching tones in English education when teachers need to tonal rising tone in the said such as anger, surprise, said in grief, sadness in the falling tone, and actively mobilize students' emotion, paying attention to the students' emotional change fluctuation; Direct at the student in different grade to carry on the scientific research, preliminary know about the reality of students' English achievement situation, understand the student's emotion dynamic and establish database; Enter the teaching stage, the students need to create a study plan firstly, teachers have to attire neat, eye kind, expression relaxed, attitude kind, gentle and cultivated manners.

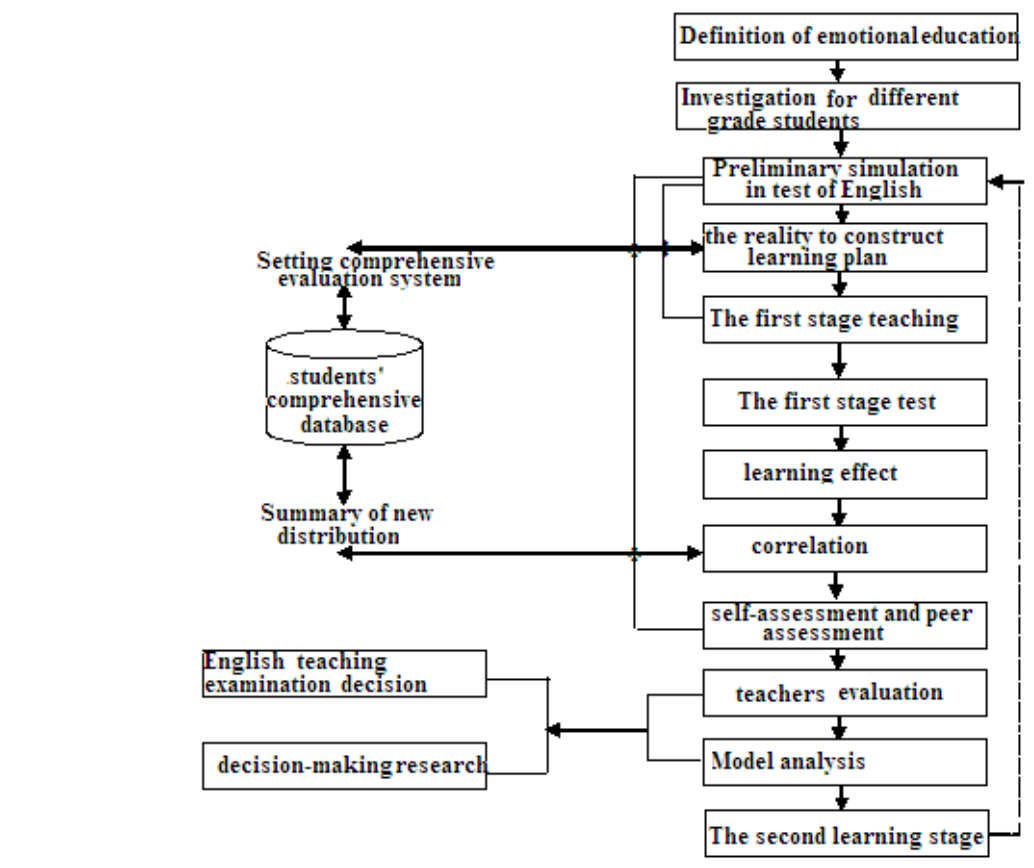

Figure 3. The improve higher vocational English learning capability model based on emotional education

\section{The grey relation analysis on optimized subjective energy efficiency performance in the model}

On the influence of model improving higher vocational English learning capability based on the emotional education to students' English result factor had a lot , in order to improve students' English achievements, we need to comprehensive analysis of students' practice the study situation, such as students' English study result related to the emotion education, reading time, the words number, cut class frequency, need to find out the biggest impact factor, we need to carry out correlation analysis, there are four students, its performance data are shown below. 


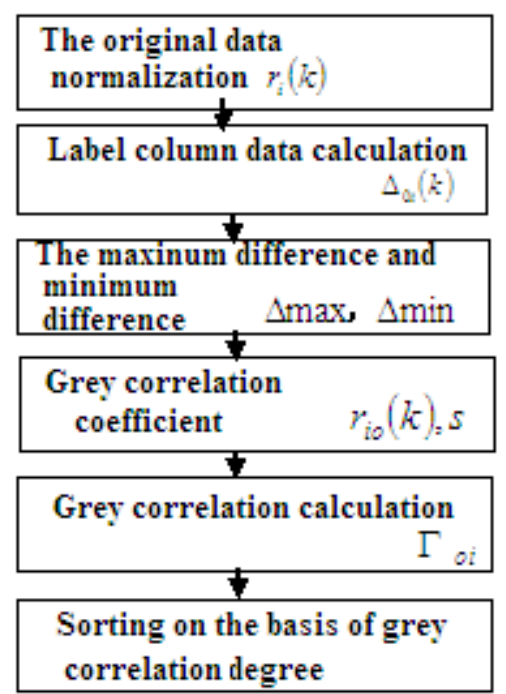

Figure 4. The grey relational analysis process of optimized subjective energy efficiency performance TABLE I. FOUR STUDENTS' ENGLISH ACHIEVEMENT AND ITS RELATED INFLUENCE FACTOR DATA

FOUR STUDENTS' ENGLISH ACHIEVEMENT AND ITS RELATED INFLUENCE F
\begin{tabular}{|l|l|l|l|l|}
\hline \multicolumn{1}{|c|}{ Influence factors } & \multicolumn{1}{|c|}{ A } & B & C & D \\
\hline Emotional education a & 80 & 77 & 86 & 89 \\
\hline Reading English time b & 7 & 9 & 15 & 18 \\
\hline Vocabulary c & 25 & 11 & 10 & 10 \\
\hline Cut class number d & 6 & 4 & 4 & 7 \\
\hline
\end{tabular}

The original data regularization, namely deduct to the original data $x_{x_{i}}(k)$ and the list of average with regularization, its computation formula as follows:

$$
r_{j}(k)=\frac{x_{i}(k)}{\sum_{A}^{c} x_{i}(k) / 4}, i=a, \ldots, d ; k=A, \ldots, D
$$

Using the affective education for column number, four students' regularization results are shown below.

TABLE II. ENGLISH ACHIEVEMENT AND ITS RELATED INFLUENCE FACTOR REGULARIZATION DATA

\begin{tabular}{|l|c|c|c|c|}
\hline \multicolumn{1}{|c|}{ Influence factors } & $\mathbf{A}$ & $\mathbf{B}$ & $\mathbf{C}$ & $\mathbf{D}$ \\
\hline $\begin{array}{l}\text { Emotional education } \\
\text { a }\end{array}$ & 0.903 & 0.965 & 1.032 & 1.079 \\
\hline $\begin{array}{l}\text { Reading English } \\
\text { time b }\end{array}$ & 0.500 & 0.820 & 0.1059 & 1.624 \\
\hline Vocabulary c & 1.430 & 1.125 & 0.361 & 1.069 \\
\hline Cut class number d & 1.324 & 0.569 & 0.907 & 1.323 \\
\hline
\end{tabular}

According to the regularization data of table 2, calculated that four students' standard column sequence difference, continue to when the emotional education a for column number difference sequence $\Delta_{o i}(k)$ the absolute value of the difference between corresponding students in the other columns $\mathrm{k}$, its computation formula is:

$$
\Delta_{o i}(k)=\left|r_{o}(k)-r_{i}(k)\right|, i=1,2,3 ; k=A, \ldots, B
$$

At this time the read English time $b$ and the difference sequence of standard series as column, the $\mathrm{k}$ difference in each element of two factors are shown below:

\begin{tabular}{|l|c|l|c|c|} 
TABLE III. & THE DIFFERENCE SEQUENCE DATA \\
\hline Difference sequence & A & B & C & D \\
\hline$\Delta_{o 1}(k)$ & 0.421 & 0.158 & 0.040 & 0.550 \\
\hline$\Delta_{o 2}(k)$ & 0.528 & 0.159 & 0.670 & 0.021 \\
\hline$\Delta_{o 3}(k)$ & 0.398 & 0.412 & 0.068 & $0 . .62$ \\
\hline
\end{tabular}

According to the table, data maximum difference $\Delta$ max and minimum difference $\Delta \mathrm{min}$, in this paper define the maximum difference and minimum difference is: $\Delta \max =\max _{i, k} \Delta_{o i}(k)$; $\Delta \min =\min _{i, k} \Delta_{o i}(k)$.

After calculation can conclude: the maximum difference $\Delta_{02}(3)=0.667$, minimum

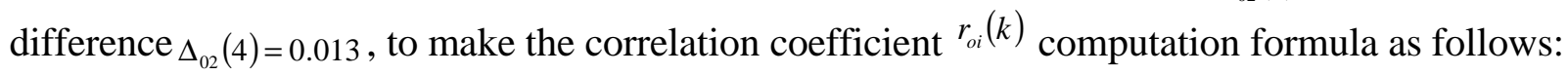




$$
r_{o i}(k)=\frac{\Delta \min +\varsigma \Delta \max }{\Delta_{o i}(k)+\varsigma \Delta \max }
$$

In formula (3), adjust coefficient, take value is 0.5 in here, into the, get correlation coefficient, the results are shown below:

TABLE IV. THE GRAY RELATIONAL COEFFICIENT BASED ON THE DIFFERENCE
\begin{tabular}{|l|c|c|c|c|}
\hline Difference sequence & A & B & C & D \\
\hline$\Delta_{o 1}(k)$ & 0.434 & 0.689 & 0.923 & 0.403 \\
\hline$\Delta_{o 2}(k)$ & 0.411 & 0.702 & 0.356 & 0.999 \\
\hline$\Delta_{o 3}(k)$ & 0.456 & 0.471 & 0.861 & 0.879 \\
\hline
\end{tabular}

According to the data in the table were calculated gray relational degree $\Gamma_{o i}$ and its computation formula is as follows:

$$
\Gamma_{o i}=\frac{\sum_{k=A}^{D} \gamma_{o i}(k)}{4}
$$

It can be counted. Sorting with income data, grey relational sequence results:, thus can be concluded that the main factor affect on the students' scores in the mode is students vocabulary.

According to the grey relational grade analysis, analyzing the influence factor of optimized subjective energy efficiency performance on the model, can discover the correlation factor for the influence degree of improving higher vocational English ability model, further to excavate influence on the development trend of the model structure through data, thus in the link of English teacher exchange decision and research to master students' comprehensive performance change in the model , to make scientific decisions for the next stage learning.

\section{Conclusion}

Teaching is a kind of emotional experience, the problem is even more in the higher vocational English teaching. Emotional education role to the ability for a learner who to participate in these question actively is very important, emotional learning environment is one of the key ability on teachers. The teacher in the English teaching process to be able to inspire students' thinking, stimulate the students' mind, to enlighten students' emotional activities correct observation and analysis of students' psychological and emotional change, adjust to teaching mode in time , in the higher vocational English teaching the emotional education will be throughout the whole teaching activity, to deepen our students' holistic view and systematic understanding, to improve the theory knowledge and practical application ability in English language.

\section{References}

[1] ZhaoDingran.Emotional education: The emotional education in teaching [J]. Education teaching BBS, 2012 (11):13-15

[2] WangLingLing. Pay attention to use emotional education, the comprehensive promotion in quality education, talk about how to permeate emotion education in the teaching of English [J].China science and technology innovation guide,2011 (30):123-127

[3] XiaoXie.English teacher professional skill training brief tutorial[M].The higher education press, 2009:156-164

[4] QiuDeHui. The mathematical emotional learning[M].Hunan people's publishing house, 2011 : 342-363.

[5] YuJin. Management [M].China university of geosciences press,2006:233-236

[6] LiuDao..English essays education [M].Beijing foreign languages university press, 2011:421-429.

[7] DayongQin.English curriculum standard[M].The people's education press, 2009 : 345-348.

[8] LuYapei.Quality education series book [M].Beijing people's publishing house,2010:78-83.

[9] GaoZhenran.Emotional teaching psychology [M]. Shanghai education press, 2012: 189-210.

[10] JianZhenFu.The decision analysis and management[M]. Tsinghua university press, 2007: 354433. 